\title{
Implication of Ccr4-Not complex function in mRNA quality control in Saccharomyces cerevisiae
}

\author{
JANNIE ASSENHOLT, ${ }^{1}$ JOHN MOUAIKEL, ${ }^{1,2}$ CYRIL SAGUEZ, ${ }^{1,3}$ MATHIEU ROUGEMAILLE, ${ }^{1,2}$ \\ DOMENICO LIBRI, ${ }^{1,2}$ and TORBEN HEICK JENSEN ${ }^{1,4}$ \\ ${ }^{1}$ Centre for mRNP Biogenesis and Metabolism, Department of Molecular Biology, Aarhus University, 8000 Aarhus C., Denmark \\ ${ }^{2}$ Centre National de la Recherche Scientifique, Centre de Genetique Moleculaire, 91190 Gif sur Yvette, France
}

\begin{abstract}
Production of messenger ribonucleoprotein particles (mRNPs) is subjected to quality control (QC). In Saccharomyces cerevisiae, the RNA exosome and its cofactors are part of the nuclear QC machinery that removes, or stalls, aberrant molecules, thereby ensuring that only correctly formed mRNPs are exported to the cytoplasm. The Ccr4-Not complex, which constitutes the major $S$. cerevisiae cytoplasmic deadenylase, has recently been implied in nuclear exosome-related processes. Consistent with a possible nuclear function of the complex, the deletion or mutation of Ccr4-Not factors also elicits transcription phenotypes. Here we use genetic depletion of the Mft1p protein of the THO transcription/mRNP packaging complex as a model system to link the Ccr4-Not complex to nuclear mRNP QC. We reveal strong genetic interactions between alleles of the Ccr4-Not complex with both the exosomal RRP6 and MFT1 genes. Moreover, Rrp6p-dependent in vivo QC phenotypes of $\Delta \mathrm{mft} 1$ cells can be rescued by codeletion of several Ccr4-Not components. We discuss how the Ccr4-Not complex may connect with the mRNP QC pathway.
\end{abstract}

Keywords: Ccr4-Not complex; RNA exosome; RNA quality control

\section{INTRODUCTION}

In Saccharomyces cerevisiae, cotranscriptional formation and release of messenger ribonucleoprotein particles (mRNPs) rely on a functional THO complex (for reviews, see Schmid and Jensen 2008; Rougemaille et al. 2008b; Rondon et al. 2010). Deletion of one of the individually inessential subunits of this tetrameric assembly (Chavez et al. 2000) leads to several defects (Rougemaille et al. 2007, 2008a; Saguez et al. 2008), among which is a decreased recruitment of the essential mRNP maturation and export factor Sub2p (Strasser et al. 2002; Zenklusen et al. 2002). As a consequence, mRNA biogenesis is severely compromised, leaving a fraction of nascent mRNA retained in nuclear "dots" at or near the site of transcription (Jensen et al. 2001a, 2004; Libri et al. 2002; Zenklusen et al. 2002; Thomsen et al. 2003; Rougemaille et al. 2007, 2008a). Whereas retained RNA is remarkably stable (Rougemaille

\footnotetext{
${ }^{3}$ Present address: Commissariat a l'Energie Atomique, Institut de Biologie et de Technologies de Saclay, 91101 Gif sur Yvette, France.

${ }^{4}$ Corresponding author.

E-mail thj@mb.au.dk.

Article published online ahead of print. Article and publication date are at http://www.rnajournal.org/cgi/doi/10.1261/rna.2919911.
}

et al. 2007), another pronounced phenotype of THO/Sub2 mutants is that of decreased mRNA levels and transcript $3^{\prime}$ end truncation (Libri et al. 2002; Rougemaille et al. 2007). This presumably occurs due to the combined effects of $3^{\prime}-5^{\prime}$ RNA degradation and defects in transcription elongation/ termination (Jensen et al. 2001b, 2004; Libri et al. 2002; Saguez et al. 2008). Finally, in THO-deletion strains, several gene $3^{\prime}$ ends become trapped in a complex containing at least the transcribed locus itself, its nascent RNA, $3^{\prime}$ end processing factors, and nuclear pore complex (NPC) components (Rougemaille et al. 2008a). This complex has been suggested to contain a mRNP intermediate stalled in the process of acquiring nuclear export competence. Its formation leads to the differential partitioning of multiple genomic loci in standard chromation preparations, a phenomenon referred to as differential chromatin fractionation (DCF).

Given the strong phenotypes at the nascent mRNA/ mRNP level, THO-deletion mutants have provided a popular test system for mRNA quality control (QC). Although the precise flaw inflicted to mRNP production is not delineated, data suggest that malfunctioning of the $3^{\prime}$ end cleavage/polyadenylation factor, $\mathrm{CPF}$, resulting in inefficient RNA 3' end polyadenylation, may be the direct cause of several of the observed defects (Saguez et al. 2008). 
Interestingly, all of the mentioned phenotypes depend on the nuclear-specific $3^{\prime}-5^{\prime}$ exonuclease Rrp6p of the $S$. cerevisiae nuclear exosome (Libri et al. 2002; Rougemaille et al. 2008a). Rrp6p is one of two active subunits of the nuclear exosome, which functions in a variety of exo- and endonucleolytic activities, e.g., processing of stable nuclear and nucleolar RNAs as well as degradation of malformed nuclear transcripts (for reviews, see Houseley and Tollervey 2009; Lykke-Andersen et al. 2009; Tomecki et al. 2010). The role of Rrp6p in mRNA QC is apparent when examining HSP104 RNA in THO mutants codeleted for Rrp6p: Lowered RNA levels, the $3^{\prime}-5^{\prime}$ end truncation bias, DCF formation, and transcription site-linked RNA dots are all phenotypes abolished by RRP6 deletion (Libri et al. 2002; Rougemaille et al. 2007, 2008a). A current model for Rrp6p-dependent QC posits that 3' end polyadenylation is constantly challenged by nuclear exonucleolysis (Saguez et al. 2008). In a THO-deletion background, polyadenylation efficiency is decreased, thereby creating an opportunity for Rrp6p to elicit 3'-5' degradation of the nascent RNA. Consistent with this idea, the catalytic activity of Rrp6p is essential for triggering RNA QC phenotypes in THO mutants (Assenholt et al. 2008). Rrp6p-challenged mRNA biogenesis may then in turn also lead to the slow release of nascent RNA, triggering DCF formation.

\section{A}

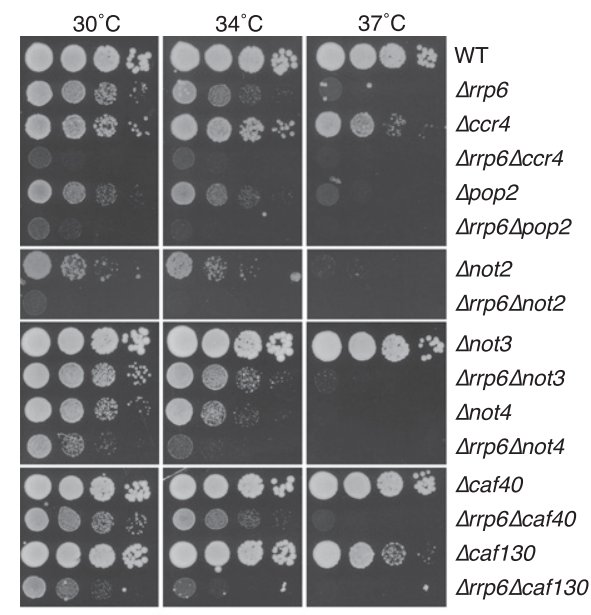

Recently, a functional link between the RNA exosome and the Ccr4-Not complex was established, suggesting that Ccr4Not might be connecting the exosome to its coactivator TRAMP (Azzouz et al. 2009), a complex that stimulates many exosomal activities, including RNA QC (LaCava et al. 2005; Vanacova et al. 2005; Wyers et al. 2005; Rougemaille et al. 2007). The Ccr4-Not complex consists of at least nine subunits, including the major cytoplasmic deadenylase activity in S. cerevisiae, Ccr4p, and Pop2p/Caf1p (Liu et al. 1998; Chen et al. 2001; Tucker et al. 2001). Due to its role in bulk mRNA deadenylation, the cytoplasmic localization of Ccr4Not is not unexpected (Tucker et al. 2001, 2002); however, the complex has also been implicated in transcription regulation (Denis 1984; Sakai et al. 1992; Collart and Struhl 1994, Deluen et al. 2002; Lenssen et al. 2002) and shown to physically associate with transcription-related factors and complexes such as the Mediator, TBP, TFIID, Paflp, SAGA (Benson et al. 1998; Chang et al. 1999; Badarinarayana et al. 2000, Liu et al. 2001), and, recently, RNA polymerase II (RNAPII) (Kruk et al. 2011). Thus, a nuclear localization is demonstrated, which has been suggested to occur particularly under stress conditions (Collart and Timmers 2004). In line with this, a human homolog of Pop2p/Caf1p, hCaf1, shows differential subcellular localization during cell cycle progression in HeLa cells (Morel et al. 2003).

B
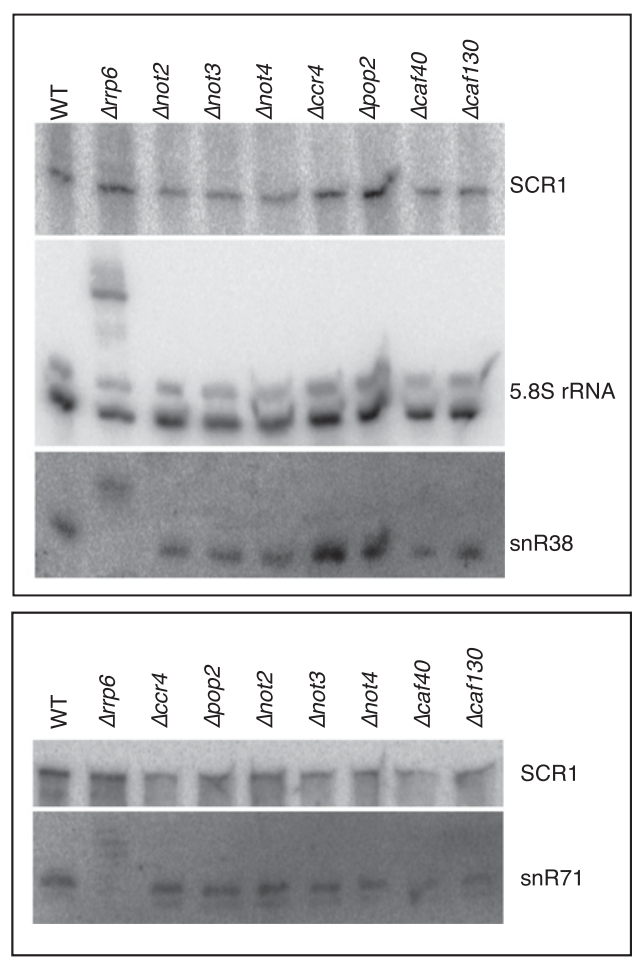

FIGURE 1. Genetic interactions between RRP6 and Ccr4-Not complex genes. ( $A$ ) The indicated single- and double-deletion strains were spotted in 10-fold dilutions onto YM1 plates and incubated for $3 \mathrm{~d}$ at the indicated temperatures. $(B)$ Northern blotting analysis of total RNA purified from the indicated strains grown at $25^{\circ} \mathrm{C}$. Membranes were probed for established Rrp6p substrates, snR38 and 5.8S rRNA (top) as well as snR71 (bottom), as indicated. A SCR1 RNA probe was used as a loading control. 
By using THO-defective cells as a model system for mRNP deficiency, we report genetic and biochemical evidence for a novel role of the Ccr4-Not complex in nuclear mRNP QC.

\section{RESULTS AND DISCUSSION}

\section{Strong genetic interactions between subunits of the Ccr4-Not complex and RRP6}

To initiate our investigation into a possible functional connection between the Ccr4-Not complex and Rrp6p, we combined the $\Delta$ rrp6 mutant of the W303 strain background with individual viable deletions of the Ccr4-Not complex genes and compared the growth capabilities of the resulting double mutants at different temperatures with that of their parental single deletions. Codeletion of RRP6 with CCR4, POP2, or
NOT2 genes robustly reduced growth compared to the single deletions at $30^{\circ} \mathrm{C}$ and $34^{\circ} \mathrm{C}$ (Fig. 1A). A more subtle interaction was observed with NOT4 and CAF130, and no genetic interactions were found between RRP6 and NOT3 or CAF40. This overall confirmed and extended previous genetic data (Azzouz et al. 2009), although strain background differences were also noticeable; e.g., we were unable to obtain viable spores from a cross between $\Delta \operatorname{rrp} 6$ and $\Delta$ not5 (data not shown). The observed genetic interaction may be based on the previously reported physical interactions between the nuclear exosome and Ccr4-Not components (Azzouz et al. 2009).

It was proposed that the Ccr4-Not complex participates with the exosome in the processing of stable RNAs, e.g., snoRNAs (Azzouz et al. 2009). We therefore tested whether the deletion of Ccr4-Not complex subunits interfered with the $3^{\prime}$ end processing of known Rrp6p targets such as
A

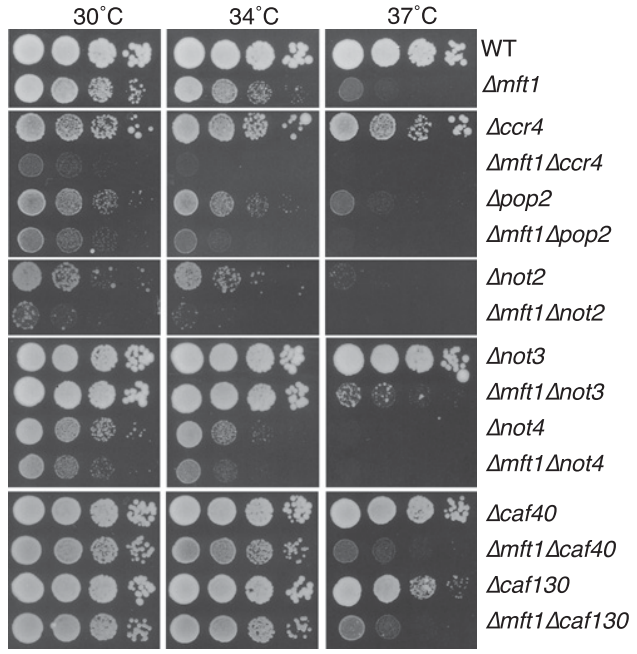

C

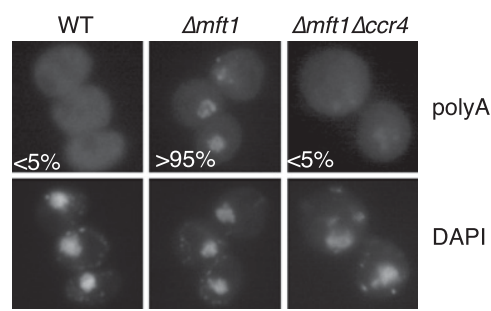

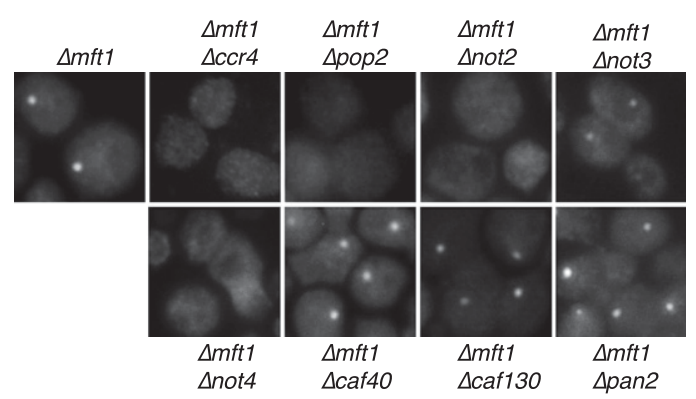

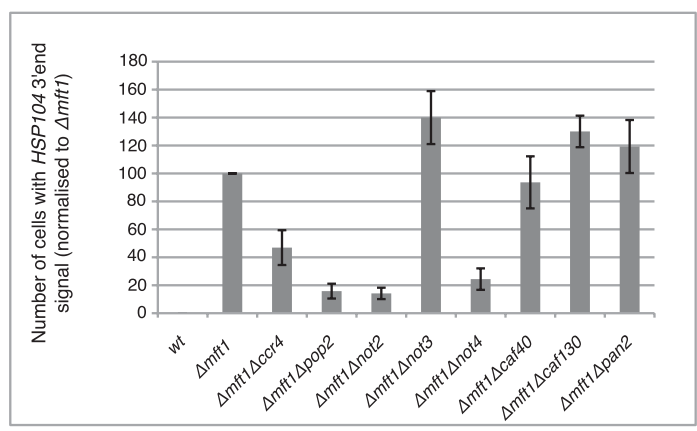

FIGURE 2. Ccr4-Not complex components are implicated in mRNA QC. (A) Genetic interactions between MFT1 and Ccr4-Not complex genes. The indicated strains were spotted onto YM1 plates in 10 -fold dilutions and incubated for $3 \mathrm{~d}$ at the indicated temperatures. Note that a growth defect of the $\Delta m f t 1 \Delta$ not 2 strain over the respective single deletions is undetectable after only $2 \mathrm{~d}$ of growth (Saguez et al. 2008). (B) HSP104 3' end RNA FISH analysis of the indicated strains. Exponentially growing cells were incubated for $15 \mathrm{~min}$ at $37^{\circ} \mathrm{C}$, fixed, and subjected to $H S P 104$ RNA-FISH visualization using Cy3-labeled probes targeted toward the $3^{\prime}$ end of the transcript (top). The fraction of cells with the FISH signal in a given experiment was quantified from three independent experiments and normalized to the result of the $\Delta m f t 1$ strain (bottom), which in these experiments had $51 \% \pm 6 \%$ of cells with positive HSP104 $3^{\prime}$ end signal. $(C)$ poly $(A)^{+}$RNA FISH analysis of the indicated strains performed as in $B$. A Cy3-labeled, LNA-modified $\mathrm{dT}_{20}$ probe was used for polyA targeting, and DAPI staining was used to visualize the chromatin-rich part of the nucleus. The fractions of cells from a representative experiment harboring strong nuclear poly $(A)^{+} \mathrm{RNA}$ accumulation are indicated. 
snoRNA38 (snR38), snoRNA71 (snR71), or 5.8S rRNA (Allmang et al. 1999; van Hoof et al. 2000; Peng et al. 2003). As shown in Figure 1B, no major processing defects or RNA level defects were evident in the Ccr4-Not deletions. Only RNA purified from $\Delta$ rrp6 cells exhibited the typical unprocessed $5.8 \mathrm{~S}+30 \mathrm{nt}$ rRNA species as well as $3^{\prime}$ end extended snR38 and snR71. Although other RNA substrates (e.g., U14) were reportedly $3^{\prime}$ end extended in strains deleted of selected Ccr4-Not complex subunits, these effects were moderate as compared to the defects in $\Delta r r p 6$ cells (Azzouz et al. 2009) and were not readily visible in our hands (data not shown). Thus, the basis for the genetic interactions between RRP6 and Ccr4-Not subunit genes is likely to also involve other substrates.

\section{Functional links between the Ccr4-Not complex and mRNA QC}

Next we turned our focus to mRNA QC. To this end, we analyzed the growth capabilities of double-deletion mutants of the $\Delta m f t 1$ allele combined with individual Ccr4-Not gene deletions (Fig. 2A). Of the tested genes, CCR4, POP2, NOT2, and NOT4 interact with MFT1. Consistently, a synthetic lethal interaction between $\Delta c c r 4$ and the deletion of the THO complex component HPR1 gene was reported (Chavez et al. 2000). No genetic interactions could be seen for NOT3, CAF40, and CAF130. These results suggest a functional relationship between the Ccr4-Not and THO complexes, possibly associated with mRNA QC.

To assay for RNA QC phenotypes, we first employed HSP104 RNA FISH analysis. Exponentially growing cells were exposed to a $15-\mathrm{min}, 37^{\circ} \mathrm{C}$ heat shift to induce transcription of the HSP104 gene. Subsequently, the cells were fixed, and HSP104 RNA was visualized employing fluorescently labeled oligonucleotide probes directed toward the $3^{\prime}$ end of the transcript. As previously reported, the deletion of the MFT1 gene led to the appearance of one intense HSP104 dot signal per cell nucleus (Fig. 2B, top), overlapping the chromatin-associated DAPI signal (data not shown) and thus indicating retention at or near the transcription site. However, combining $\Delta m f t 1$ with $\Delta c c r 4$, $\Delta$ pop2, $\Delta$ not2, or $\Delta$ not 4 all caused a decrease in the number of cells harboring the HSP104 RNA dot (Fig. 2B, top and bottom). The NOT3, CAF40, and CAF130 deletions all left the intensity of the $\Delta m f t 1$ dot unchanged, much like the negative control, a deletion of the PAN2 deadenylase gene. We note a correlation between the Ccr4-Not subunits required for HSP104 RNA dot formation (Ccr4p, Pop2p, Not2p, and Not4p) and the strengths of the synthetic negative interactions of their deletions with $\Delta m f t 1$ (Fig. 2A) and $\Delta \operatorname{rrp6}$ (Fig. 1A). The generality of relief of $\Delta m f t 1$-induced RNA retention by the CCR4 deletion was tested using a fluorescently labeled oligo$\mathrm{dT}_{20}$ LNA-modified probe and resulted in a similar conclusion (Fig. 2C).

\section{Loss of HSP104 dots is not based on decreased transcription}

Given the reported role of Ccr4-Not in transcription regulation (Denis and Malvar 1990; Collart and Struhl 1994; Benson et al. 1998; Liu et al. 1998; Deluen et al. 2002; Lenssen et al. 2002, 2005; Kruk et al. 2011), it was essential to investigate the possibility that the disappearance of the HSP104 RNA FISH signal in the affected double deletions was not simply due to the reduced transcription levels imposed by the added Ccr4-Not gene deletion. We therefore tested HSP104 gene transcription activity by two different approaches. First, we measured the levels of nascent HSP104 RNA by utilizing $5^{\prime}$ end RNA-FISH probes. Since none of the tested single-deletion mutants exhibited HSP104 RNA retention as evaluated by HSP104 RNA 3' end probes (data not shown), this analysis provided a simple surrogate transcription assay. As controls, we included the rpb1-1 and rad3-7.7 mutant strains, which were previously shown to be

A

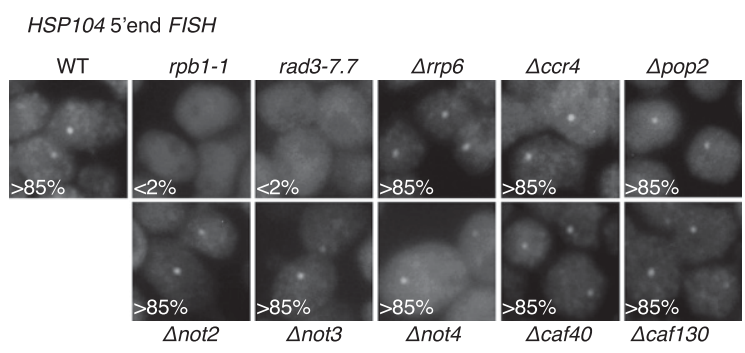

B

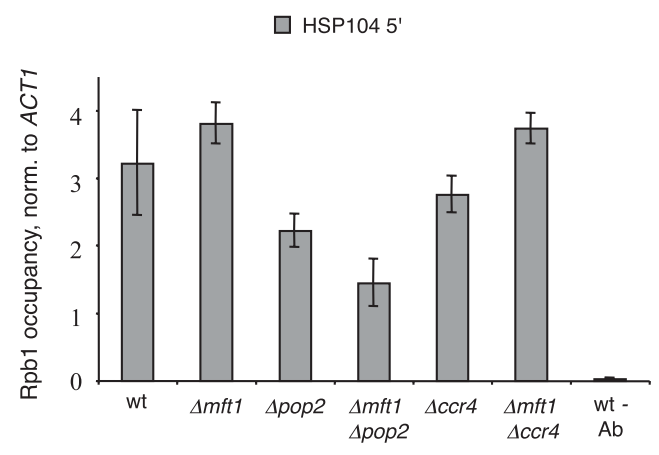

FIGURE 3. HSP104 gene transcription levels are not affected by Ccr4-Not gene deletion. (A) HSP104 5' end RNA FISH analysis of the indicated strains. Exponentially growing cells were incubated for 15 min at $37^{\circ} \mathrm{C}$, fixed, and subjected to HSP104 RNA visualization using Cy3-labeled probes targeted toward the $5^{\prime}$ end of the transcript. Wildtype (WT), as well as rpb1-1 and rad3-7.7, cells served as positive and negative controls, respectively. The fractions of cells from a representative experiment, harboring a positive HSP104 $5^{\prime}$ end signal, are indicated. (B) ChIP analysis of RNAPII (Rpblp). Y80 antibody recognizing the $\mathrm{N}$ terminus of Rpblp was used to precipitate chromatin from the indicated cells grown exponentially and heat-shifted for $15 \mathrm{~min}$ to $37^{\circ} \mathrm{C}$ before formaldehyde cross-linking. HSP104 gene $5^{\prime}$ end levels were measured by qPCR (output to input ratio) and normalized to Rbplp ChIP signal for the ACT1 gene. Average signals and SDs were derived from three independent IP experiments. 
defective in transcription initiation at elevated temperatures (Nonet et al. 1987; Jensen et al. 2004). Apart from these negative controls, all the strains displayed a distinct nuclear HSP104 RNA dot signal (Fig. 3A). Second, we subjected $\Delta c c r 4$ and $\Delta p o p 2$ cells, as well as their respective double deletions with $\Delta m f t 1$, to RNAPII chromatin immunoprecipitation (ChIP) assays using an antibody directed toward the $\mathrm{N}$ terminus of Rpblp, the largest subunit of RNAPII. As shown in Figure 3B, RNAPII levels at the HSP104 gene $5^{\prime}$ end in the $\Delta m f t 1, \Delta p o p 2, \Delta m f t 1 \Delta p o p 2, \Delta c c r 4$, and $\Delta m f t 1 \Delta c c r 4$ cells were not, or were only mildly, affected compared with a wild-type (WT) control background. We therefore conclude that HSP104 RNA retention in $\Delta m f t 1$ is not abolished by these gene deletions because of decreased transcription activity but rather because of a defective mRNP QC system (see also below).

\section{DCF and HSP104 RNA $3^{\prime}$ end truncation in $\Delta \mathrm{mft} 1$ are suppressed by deletion of CCR4 or POP2}

We next turned to two other assays linked to aberrant HSP104 RNA biogenesis in $\Delta m f t 1$ cells: DCF formation and RNA degradation. These analyses were focused on the
$\Delta$ pop2 and $\Delta c c r 4$ gene deletions. DCF formation was assessed in cells grown for $15 \mathrm{~min}$ at $37^{\circ} \mathrm{C}$ and formaldehyde cross-linked as previously described (Rougemaille et al. 2008a). Since DCF is preferentially localized at the $3^{\prime}$ end of genes, its formation was interrogated by qPCR using amplicons specific for the $5^{\prime}$ and $3^{\prime}$ ends of the HSP104 gene. The approximately 10 -fold increase in HSP104 DNA $3^{\prime}$ ends pelleted from $\Delta m f t 1$ compared with WT cells was strongly decreased by both POP2 and CCR4 codeletion (Fig. 4A). The $\Delta p o p 2$ and $\Delta c c r 4$ single deletions showed only marginal DCF formation. Consistently, the HSP104 RNA $3^{\prime}-5^{\prime}$ end truncation bias measured in the total RNA preparation from $\triangle m f t 1$ cells was also fully restored by the codeletion of POP2 or CCR4 (Fig. 4B,C). The generally low level of HSP104 RNA in the $\Delta m f t 1$ background was not restored by $\Delta p o p 2$ or $\Delta c c r 4$. We conclude that Ccr4p and Pop2p help induce mRNA degradation and DCF formation in a THO gene-deletion background.

\section{CONCLUSIONS}

We report that four subunits of the Ccr4-Not complex-Ccr4p, Pop2p, Not2p, and Not4p-severely impact HSP104 RNA

A

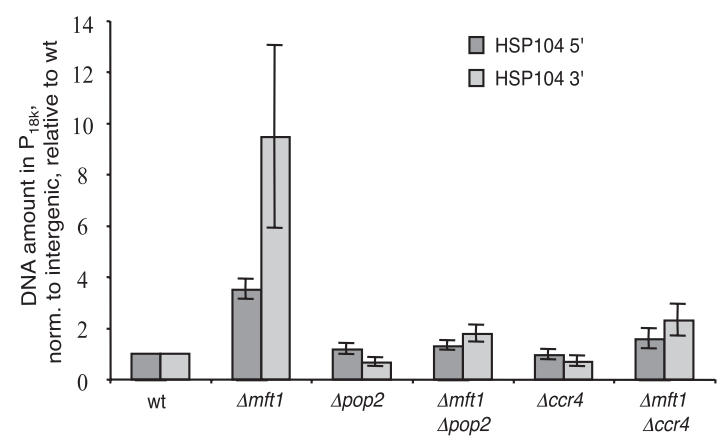

B

C
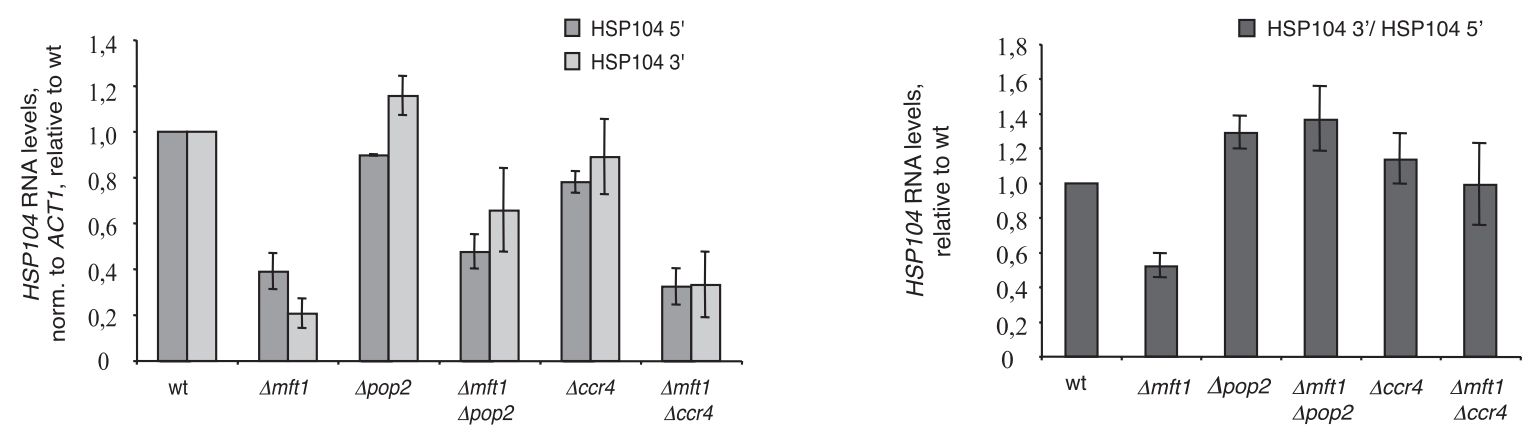

FIGURE 4. DCF and HSP104 $3^{\prime}$ end truncation-phenotypes of $\triangle m f t 1$ cells are restored upon POP2 or CCR4 codeletion. (A) DCF (DNA content in the "P18k" pellet obtained after a $18000 \mathrm{~g}$ centrifugation step) was measured using qPCR amplicons directed toward the $5^{\prime}$ or 3 ' ends of the HSP104 gene. DNA amounts were normalized to an intergenic region in chromosome V and plotted as arbitrary units relatively to the wild-type (WT) sample. Average signals and SDs reflect DCF enrichment from three independent experiments. (B) HSP104 RNA 5' and 3' end levels were quantified by RT-qPCR analysis of total RNA preparations from the same cell cultures and using the same amplicons as in A. HSP104 RNA amounts in different mutant backgrounds are plotted relative to the WT after normalization to ACT1 RNA. (C) HSP104 3' end/5' end ratios plotted relative to the WT sample. In $B$ and $C$, the average signals and SDs were derived from three independent experiments. 
transcription site-associated retention induced by MFT1 gene deletion. Moreover, the removal of these genes results in synthetic growth phenotypes when combined with both the $\Delta m f t 1$ or $\Delta \operatorname{rrp} 6$ deletions. The latter result implies that the need for Ccr4-Not function in an $\Delta m f t 1$ context may go through Rrp6p. Although the data link Ccr4-Not to nuclear $\mathrm{mRNP}$ QC in S. cerevisiae, they do not allow us to conclude whether one component is central or whether the entire complex is involved. This is because individual subunits affect the integrity of the complex; e.g., the interaction between Ccr4p and the rest of the complex is lost in a $\Delta p o p 2$ background (Bai et al. 1999), and complex formation is dependent on Not2p (Russell et al. 2002).

Given its intimate connection to transcription, and possibly transcription-coupled processes, Ccr4-Not may generally challenge mRNP quality in THO mutants in a way that is eventually detected by an Rrp6p-dependent mechanism. The Ccr4-Not complex could, e.g., be required as a structural component of the QC machinery, perhaps mediating the assembly of a functional Rrp6p-containing complex. This is consistent with the physical interactions reported between several Ccr4-Not components and the RNA exosome (Azzouz et al. 2009). Another possibility is that Ccr4p deadenylase activity is carried out successively with Rrp6p function and that the combination of both activities results in RNA retention. Finally, as the presence of RNA appears to prevent exosome-Ccr4-Not complex interaction (Azzouz et al. 2009), the lack of Ccr4p deadenylation activity may alter the nature of its exosome interaction. Regardless of the mechanistic details, the evidence presented here should inspire further analysis into the functional relationships among Ccr4Not, TRAMP, and the RNA exosome in nuclear mRNP QC.

\section{MATERIALS AND METHODS}

\section{Plasmids, strains, and growth assays}

All strains were derived from the $S$. cerevisiae W303 background, and gene deletions as well as strain crosses were done using standard procedures. For yeast plating assays, exponentially growing cells were spotted onto YM1 plates in 10-fold dilutions starting at $\mathrm{OD}=0.3$ and incubated for $3 \mathrm{~d}$ at $30^{\circ} \mathrm{C}, 34^{\circ} \mathrm{C}$, or $37^{\circ} \mathrm{C}$.

\section{RNA-FISH analysis}

HSP104 RNA localization was probed on fixed cells grown for 15 min at $37^{\circ} \mathrm{C}$ as previously described (Jensen et al. 2001b; Thomsen et al. 2003). Cy3-labeled FISH probes were as follows: HSP104 RNA 3' end (THJ203-206) (Jensen et al. 2001b), HSP104 RNA 5' end (THJ361-364) (Thomsen et al. 2008), or an LNA-modified $\mathrm{dT}_{20}$ probe (Thomsen et al. 2005). Slide processing and image preparation were done as previously described (Thomsen et al. 2005).

\section{DNA and RNA preparations}

Northern blotting, heavy chromatin, RT-qPCR, and Rpb1p ChIP analyses were performed as previously described (Midtgaard et al.
2006; Rougemaille et al. 2007, 2008a; Assenholt et al. 2008), except that chromatin extracts were immunoprecipitated using an antiRpblp polyclonal antibody (Y-80, Santa-Cruz) preconjugated to Dynabeads-protein A (Invitrogen). A $5^{\prime}$ end radiolabeled probe (5' AGATCTGAGTGAGCTGAGAAGG-3' ${ }^{\prime}$ ) was used for snR71 Northern hybridization.

\section{ACKNOWLEDGMENTS}

We thank Bertrand Seraphin for $\Delta$ not2, $\Delta$ not 3 , and $\Delta$ not 4 strains, as well as Martine Collart for Ccr4p antibody. C.S. was supported by a fellowship from the Federation of Biochemical Societies (FEBS) association. The work was otherwise supported by the Danish National Research Foundation (D.L. and T.H.J.), the Danish Cancer Society (T.H.J.), and the CNRS (D.L.). The research was carried out within the scope of the Associated European Laboratory LEA "Laboratory of Nuclear RNA Metabolism."

Received July 6, 2011; accepted July 12, 2011.

\section{REFERENCES}

Allmang C, Kufel J, Chanfreau G, Mitchell P, Petfalski E, Tollervey D. 1999. Functions of the exosome in rRNA, snoRNA and snRNA synthesis. EMBO J 18: 5399-5410.

Assenholt J, Mouaikel J, Andersen KR, Brodersen DE, Libri D, Jensen TH. 2008. Exonucleolysis is required for nuclear mRNA quality control in yeast THO mutants. RNA 14: 2305-2313.

Azzouz N, Panasenko OO, Colau G, Collart MA. 2009. The CCR4NOT complex physically and functionally interacts with TRAMP and the nuclear exosome. PLoS ONE 4: e6760. doi: 10.1371/ journal.pone.0006760.

Badarinarayana V, Chiang YC, Denis CL. 2000. Functional interaction of CCR4-NOT proteins with TATAA-binding protein (TBP) and its associated factors in yeast. Genetics 155: 1045-1054.

Bai Y, Salvadore C, Chiang YC, Collart MA, Liu HY, Denis CL. 1999. The CCR4 and CAF1 proteins of the CCR4-NOT complex are physically and functionally separated from NOT2, NOT4, and NOT5. Mol Cell Biol 19: 6642-6651.

Benson JD, Benson M, Howley PM, Struhl K. 1998. Association of distinct yeast Not2 functional domains with components of Gen5 histone acetylase and Ccr4 transcriptional regulatory complexes. EMBO J 17: 6714-6722.

Chang M, French-Cornay D, Fan HY, Klein H, Denis CL, Jaehning JA. 1999. A complex containing RNA polymerase II, Paflp, Cdc73p, Hprlp, and Ccr4p plays a role in protein kinase $\mathrm{C}$ signaling. $\mathrm{Mol}$ Cell Biol 19: 1056-1067.

Chavez S, Beilharz T, Rondon AG, Erdjument-Bromage H, Tempst P, Svejstrup JQ, Lithgow T, Aguilera A. 2000. A protein complex containing Tho2, Hpr1, Mft1 and a novel protein, Thp2, connects transcription elongation with mitotic recombination in Saccharomyces cerevisiae. EMBO J 19: 5824-5834.

Chen J, Rappsilber J, Chiang YC, Russell P, Mann M, Denis CL. 2001. Purification and characterization of the 1.0 MDa CCR4-NOT complex identifies two novel components of the complex. J Mol Biol 314: 683-694.

Collart MA, Struhl K. 1994. NOT1(CDC39), NOT2(CDC36), NOT3, and NOT4 encode a global-negative regulator of transcription that differentially affects TATA-element utilization. Genes Dev 8: 525537.

Collart MA, Timmers HT. 2004. The eukaryotic Ccr4-not complex: a regulatory platform integrating mRNA metabolism with cellular signaling pathways? Prog Nucleic Acid Res Mol Biol 77: 289-322.

Deluen C, James N, Maillet L, Molinete M, Theiler G, Lemaire M, Paquet N, Collart MA. 2002. The Ccr4-not complex and yTAF1 
(yTaf(II)130p/yTaf(II)145p) show physical and functional interactions. Mol Cell Biol 22: 6735-6749.

Denis CL. 1984. Identification of new genes involved in the regulation of yeast alcohol dehydrogenase II. Genetics 108: 833-844.

Denis CL, Malvar T. 1990. The CCR4 gene from Saccharomyces cerevisiae is required for both nonfermentative and spt-mediated gene expression. Genetics 124: 283-291.

Houseley J, Tollervey D. 2009. The many pathways of RNA degradation. Cell 136: 763-776.

Jensen TH, Boulay J, Rosbash M, Libri D. 2001a. The DECD box putative ATPase Sub2p is an early mRNA export factor. Curr Biol 11: 1711-1715.

Jensen TH, Patricio K, McCarthy T, Rosbash M. 2001b. A block to mRNA nuclear export in S. cerevisiae leads to hyperadenylation of transcripts that accumulate at the site of transcription. Mol Cell 7: 887-898.

Jensen TH, Boulay J, Olesen JR, Colin J, Weyler M, Libri D. 2004. Modulation of transcription affects mRNP quality. Mol Cell 16: 235-244.

Kruk JA, Dutta A, Fu J, Gilmour D, Reese J. 2011. The multifunctional Ccr4-Not complex directly promotes trasncription elongation. Genes Dev 25: 581-593.

LaCava J, Houseley J, Saveanu C, Petfalski E, Thompson E, Jacquier A, Tollervey D. 2005. RNA degradation by the exosome is promoted by a nuclear polyadenylation complex. Cell 121: 713-724.

Lenssen E, Oberholzer U, Labarre J, De Virgilio C, Collart MA. 2002. Saccharomyces cerevisiae Ccr4-not complex contributes to the control of Msn2p-dependent transcription by the Ras/cAMP pathway. Mol Microbiol 43: 1023-1037.

Lenssen E, James N, Pedruzzi I, Dubouloz F, Cameroni E, Bisig R, Maillet L, Werner M, Roosen J, Petrovic K, et al. 2005. The Ccr4Not complex independently controls both Msn2-dependent transcriptional activation-via a newly identified Glc7/Bud14 type I protein phosphatase module-and TFIID promoter distribution. Mol Cell Biol 25: 488-498.

Libri D, Dower K, Boulay J, Thomsen R, Rosbash M, Jensen TH. 2002. Interactions between mRNA export commitment, $3^{\prime}$-end quality control, and nuclear degradation. Mol Cell Biol 22: 8254-8266.

Liu HY, Badarinarayana V, Audino DC, Rappsilber J, Mann M, Denis CL. 1998. The NOT proteins are part of the CCR4 transcriptional complex and affect gene expression both positively and negatively. EMBO J 17: 1096-1106.

Liu HY, Chiang YC, Pan J, Chen J, Salvadore C, Audino DC, Badarinarayana V, Palaniswamy V, Anderson B, Denis CL. 2001. Characterization of CAF4 and CAF16 reveals a functional connection between the CCR4-NOT complex and a subset of SRB proteins of the RNA polymerase II holoenzyme. J Biol Chem 276: 7541-7548.

Lykke-Andersen S, Brodersen DE, Jensen TH. 2009. Origins and activities of the eukaryotic exosome. J Cell Sci 122: 1487-1494.

Midtgaard SF, Assenholt J, Jonstrup AT, Van LB, Jensen TH, Brodersen DE. 2006. Structure of the nuclear exosome component Rrp6p reveals an interplay between the active site and the HRDC domain. Proc Natl Acad Sci 103: 11898-11903.

Morel AP, Sentis S, Bianchin C, Le Romancer M, Jonard L, Rostan MC, Rimokh R, Corbo L. 2003. BTG2 antiproliferative protein interacts with the human CCR4 complex existing in vivo in three cell-cycle-regulated forms. J Cell Sci 116: 2929-2936.

Nonet M, Scafe C, Sexton J, Young R. 1987. Eucaryotic RNA polymerase conditional mutant that rapidly ceases mRNA synthesis. Mol Cell Biol 7: 1602-1611.

Peng WT, Robinson MD, Mnaimneh S, Krogan NJ, Cagney G, Morris Q, Davierwala AP, Grigull J, Yang X, Zhang W, et al. 2003. A panoramic view of yeast noncoding RNA processing. Cell 113: 919-933.

Rondon AG, Jimeno S, Aguilera A. 2010. The interface between transcription and mRNP export: from THO to THSC/TREX-2. Biochim Biophys Acta 1799: 533-538.
Rougemaille M, Gudipati RK, Olesen JR, Thomsen R, Seraphin B, Libri D, Jensen TH. 2007. Dissecting mechanisms of nuclear mRNA surveillance in $\mathrm{THO} /$ sub2 complex mutants. EMBO J 26: 2317-2326.

Rougemaille M, Dieppois G, Kisseleva-Romanova E, Gudipati RK, Lemoine S, Blugeon C, Boulay J, Jensen TH, Stutz F, Devaux F, et al. 2008a. THO/Sub2p functions to coordinate 3 '-end processing with gene-nuclear pore association. Cell 135: 308-321.

Rougemaille M, Villa T, Gudipati RK, Libri D. 2008b. mRNA journey to the cytoplasm: attire required. Biol Cell 100: 327-342.

Russell P, Benson JD, Denis CL. 2002. Characterization of mutations in NOT2 indicates that it plays an important role in maintaining the integrity of the CCR4-NOT complex. J Mol Biol 322: $27-39$.

Saguez C, Schmid M, Olesen JR, Ghazy MA, Qu X, Poulsen MB, Nasser T, Moore C, Jensen TH. 2008. Nuclear mRNA surveillance in $\mathrm{THO} /$ sub2 mutants is triggered by inefficient polyadenylation. Mol Cell 31: 91-103.

Sakai A, Chibazakura T, Shimizu Y, Hishinuma F. 1992. Molecular analysis of POP2 gene, a gene required for glucose-derepression of gene expression in Saccharomyces cerevisiae. Nucleic Acids Res 20: $6227-6233$.

Schmid M, Jensen TH. 2008. Quality control of mRNP in the nucleus. Chromosoma 117: 419-429.

Strasser K, Masuda S, Mason P, Pfannstiel J, Oppizzi M, RodriguezNavarro S, Rondon AG, Aguilera A, Struhl K, Reed R, et al. 2002. TREX is a conserved complex coupling transcription with messenger RNA export. Nature 417: 304-308.

Thomsen R, Libri D, Boulay J, Rosbash M, Jensen TH. 2003. Localization of nuclear retained mRNAs in Saccharomyces cerevisiae. RNA 9: 1049-1057.

Thomsen R, Nielsen PS, Jensen TH. 2005. Dramatically improved RNA in situ hybridization signals using LNA-modified probes. RNA 11: 1745-1748.

Thomsen R, Saguez C, Nasser T, Jensen TH. 2008. General, rapid, and transcription-dependent fragmentation of nucleolar antigens in $S$. cerevisiae mRNA export mutants. RNA 14: 706-716.

Tomecki R, Kristiansen MS, Lykke-Andersen S, Chlebowski A, Larsen KM, Szczesny RJ, Drazkowska K, Pastula A, Andersen JS, Stepien PP, et al. 2010. The human core exosome interacts with differentially localized processive RNases: hDIS3 and hDIS3L. EMBO J 29: 2342-2357.

Tucker M, Valencia-Sanchez MA, Staples RR, Chen J, Denis CL, Parker R. 2001. The transcription factor associated Ccr4 and Caf1 proteins are components of the major cytoplasmic mRNA deadenylase in Saccharomyces cerevisiae. Cell 104: 377-386.

Tucker M, Staples RR, Valencia-Sanchez MA, Muhlrad D, Parker R. 2002. Ccr4p is the catalytic subunit of a Ccr4p/Pop2p/Notp mRNA deadenylase complex in Saccharomyces cerevisiae. EMBO J 21: 1427-1436.

Vanacova S, Wolf J, Martin G, Blank D, Dettwiler S, Friedlein A, Langen H, Keith G, Keller W. 2005. A new yeast poly(A) polymerase complex involved in RNA quality control. PLoS Biol 3: e189. doi: 10.1371/journal.pbio.0030189.

van Hoof A, Lennertz P, Parker R. 2000. Yeast exosome mutants accumulate $3^{\prime}$-extended polyadenylated forms of U4 small nuclear RNA and small nucleolar RNAs. Mol Cell Biol 20: 441-452.

Wyers F, Rougemaille M, Badis G, Rousselle JC, Dufour ME, Boulay J, Regnault B, Devaux F, Namane A, Seraphin B, et al. 2005. Cryptic pol II transcripts are degraded by a nuclear quality control pathway involving a new poly(A) polymerase. Cell 121: $725-737$.

Zenklusen D, Vinciguerra P, Wyss JC, Stutz F. 2002. Stable mRNP formation and export require cotranscriptional recruitment of the mRNA export factors Yralp and Sub2p by Hprlp. Mol Cell Biol 22: $8241-8253$. 

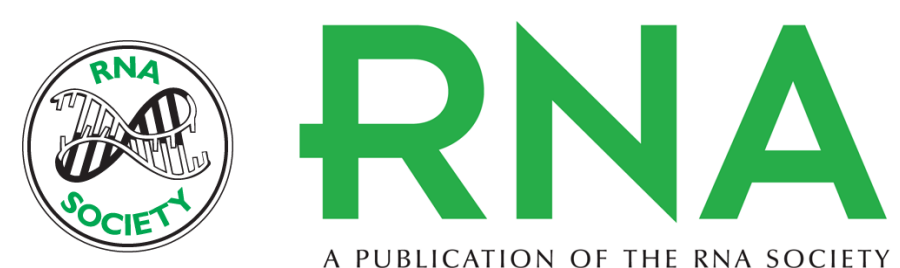

A PUBLICATION OF THE RNA SOCIETY

\section{Implication of Ccr4-Not complex function in mRNA quality control in Saccharomyces cerevisiae}

Jannie Assenholt, John Mouaikel, Cyril Saguez, et al.

RNA 2011 17: 1788-1794 originally published online August 23, 2011

Access the most recent version at doi:10.1261/rna.2919911

$\begin{array}{ll}\text { References } & \begin{array}{l}\text { This article cites } 49 \text { articles, } 23 \text { of which can be accessed free at: } \\ \text { http://rnajournal.cshlp.org/content/17/10/1788.full.html\#ref-list-1 }\end{array}\end{array}$

License

Email Alerting Receive free email alerts when new articles cite this article - sign up in the box at the Service top right corner of the article or click here. 